\title{
Prostate Cancer in Iran: Trends in Incidence and Morphological and Epidemiological Characteristics
}

\author{
Reza Pakzad ${ }^{1}$, Hosein Rafiemanesh ${ }^{1}$, Mahshid Ghoncheh ${ }^{2}$, Arezoo Sarmad ${ }^{3}$, \\ Hamid Salehiniya ${ }^{1,4,5 *}$, Sayedehafagh Hosseini ${ }^{6}$, Zahra Sepehri ${ }^{7}$, Amin Afshari- \\ Moghadam 8 ,9
}

\begin{abstract}
Background: Prostate cancer is second most common cancer in men overall in the world, whereas it is the third most common cancer in men and the sixth most common cancer in Iran. Few studies have been conducted on the epidemiology of prostate cancer in Iran. Since ethnicity of Iranian men is different from Asian people and given the epidemiologic and demographic transition taking place in Iran, this study aimed to investigate trends of incidence and morphology of prostate cancer during 2003 - 2008 in the country. Materials and Methods: Data were collected retrospectively reviewing all new prostate cancer patients in the Cancer Registry Center of the Health Deputy for Iran during a 6-year period. Also carcinoma, NOS and adenocarcinoma, NOS morphology were surveyed. Trends analysis of incidence and morphology was by joinpoint regression. Results: During the six years a total of 16,071 cases of prostate cancer were recorded in Iran. Most were adenocarcinomas at 95.2 percent. Trend analysis of incidence (ASR) There was a significant increase incidence, with annual percentage change (APC) of $17.3 \%$ and for morphology change percentage trends there was a significant decrease in adenocarcinoma with an APC of -1.24\%. Conclusions: Prostate cancer is a disease of older men and the incidence is increasing in Iran. The most common morphology is adenocarcinoma this appears to be decreasing over time. Due to the changing lifestyles and the aging of the population, epidemiological studies and planning assessment of the etiology of prostate cancer and its early detection are essential.
\end{abstract}

Keywords: Prostate cancer - trend - incidence - morphology - Iran

Asian Pac J Cancer Prev, 17 (2), 839-843

\section{Introduction}

Cancer is one of the main causes of death worldwide (Keyghobadi et al., 2015). It is predicted that by 2025, the incidence of cancer raises $45 \%$ in developing countries (Amoori et al., 2014) . Based on the GLOBOCAN report, 14090 new cases of cancer annually occur in the world and 8202 people per year die due to cancer in the world (Ferlay et al., 2015). In some countries, cancer is the second leading cause of death among all of causes of death, but in developing countries, including Iran, cancer is a major public health problem among non-communicable diseases So that after cardiovascular diseases and accidents is the third leading cause of death in Iran (Sadjadi et al., 2007; Mehrabani et al., 2008; Amoori et al., 2014).

One of the major cancers is prostate cancer so that it is second most common cancer in men in the world (Sadjadi et al., 2007) and first most common cancer in American and European men (Bray et al., 2010), while in 2012, 1.1 million men suffered from prostate cancer in the world, about $70 \%$ in developing countries (Ferlay et al., 2015). Almost $42 \%$ of prostate cancer cases occur in men over 50 years (Hosseini et al., 2007) and most cases often are seen after 60 years (Pourmand et al., 2007; Pakzad et al., 2015).

Few studies have been conducted on the epidemiology of prostate cancer in Iran (Radmard, 2010), whereas it is the third most common cancer in men and the sixth most common cancer in Iran (Goya, 2007), Prostate cancer has a different geographical distribution so that in Asian countries, including Iran, is lower than in Western countries (Hosseini et al., 2007; Autorino et al., 2009; Ferlay et al., 2015). There also is the same distribution of the cancer in Iran, as the data recorded showed that standardized incidence in 2000 in Ardabil was 3.5 per

${ }^{1}$ Department of Epidemiology, Biostatistics, school of public health, Tehran University of Medical Sciences, Tehran, ${ }^{2}$ Department of Epidemiology, Biostatistics, School of public health, Hamadan University of medical sciences, Hamadan, ${ }^{3}$ School of Allied Medical Sciences, Tehran University of Medical Sciences, ${ }^{4}$ Minimally Invasive Surgery Research Center, Iran University of Medical Sciences, ${ }^{5}$ Students' Scientific Research Center, Tehran University of Medical Sciences, ${ }^{6}$ Endometriosis Research Center, Iran University of Medical, Tehran, ${ }^{7}$ Department of internal medicine, Zabol University of medical sciences, ${ }^{8}$ Zabol University of medical sciences, Zabol, ${ }^{9}$ Shahid Beheshti University of Medical Sciences, Tehran, Iran, Iran *For correspondence: alesaleh70@yahoo.com 
100,000 people and other studies have reported the incidence of 15.6 per 100,000 people in men (Radmard, 2010), While a study conducted in the Fars province at the same time indicated that the cancer is not one of the ten most common cancers (Mehrabani et al., 2008). Different causal factors are effective on developing the cancer. These factors can be age and nutrition (Pourmand et al., 2007). Due to changes in nutrition and also older population (Amoori et al., 2014), it can be expected to change over time the incidence of prostate cancer. A study based on data from 1996 to 2000 reported the incidence of cancer about 5.1 per 100,000 people, while the incidence reached to 12.5 in 2013, which represents an increasing trend in the incidence of prostate cancer (Ferlay et al., 2015) Depending on the different cancer types, there are different morphology such as carcinoma, adenocarcinoma, sarcoma, and others have various percentages in different cancers. However, Adenocarcinoma is the most common type of prostate cancer and prevalent in patients older than 65 years (Autorino et al., 2009). Other studies have estimated the prevalence of this type of morphology nearly 91.4\% (Jamali and Moghadam, 1996). Since ethnicity Iranian men is different from Asian pepole and given epidemiologic and demographic transition taking place in Iran, this study aimed to investigate the Epidemiology Characteristics and Trends of Incidence and Morphology of Prostate Cancer, during 2003 - 2008 in Iran.

\section{Materials and Methods}

\section{Data source}

This analytic study was done based on longitudinal program in Iran. The data were collected from Cancer Registry Center report of health deputy which is based on Iran ministry of health guidelines (Goya, 2007). Data were collected retrospectively reviewing all new prostate cancer patients in Cancer Registry Center of health deputy for Iran during a 6-year period (2003 - 2008). Prostate cancer was defined as ICD-O C61 (Fritz, 2000).This study Survey Carcinoma,NOS and Adenocarcinoma,NOS with 8010/3 and 8140/3 morphology code, respectively.

\section{Statistical analysis}

Age-standardized rates of cancer incidence were calculated by the direct standardization method, using the world standard population as a reference. To describe incidence time trends, we carried out joinpoint regression analysis using the software Joinpoint Regression Program, Version 4.1.1.1 October 2014 (Kim et al., 2000). As well to evaluate the morphological changes, were obtained the percentage allocated for kind of morphological types. So to analysis morphology change percentage trends for six year, we carried out joinpoint regression analysis using the software Joinpoint Regression Program. The analysis included logarithmic transformation of the rates, standard error, maximum number of one joinpoints, and minimum of six years between zero joinpoints. All other program parameters were set to default values. The aim of the approach is to identify possible joinpoints where a significant change in the trend occurs. The method identifies joinpoints based on regression models with 0-1 joinpoints. In this study 0 joinpiont (Full model) was a significant model. The final model selected was the most parsimonious of these, with the estimated annual percent change (APC) based on the trend within each segment. In describing trends, the terms "significant increase" or "significant decrease" signify that the slope of the trend was statistically significant $(\mathrm{P}<0.05)$. All statistical tests were two sided. Other descriptive and analytical analysis using of STATA 12 software.

\section{Results}

During the study, 9-7\% of all cancers in Iranian men had prostate cancer. In total, the six-year study, 16,071 cases of prostate cancer were recorded. 79-70 year old age group with the highest number of cases to 6,783 cases $(42.20 \%)$, which was related to the morphology of adenocarcinoma, was 95\% (Table1).

Most cases occur after age 50 and age 80 to 84 years, is the peak risk for prostate cancer. About $96 \%$ of case occur the age group above 50 years old that this difference was statistically significant (P-Value <0.05) (Figure 1).

\section{Epidemiological trends}

Joinpoint analysis showed a significant increase in the standardized incidence rate of prostate cancer in iran. The

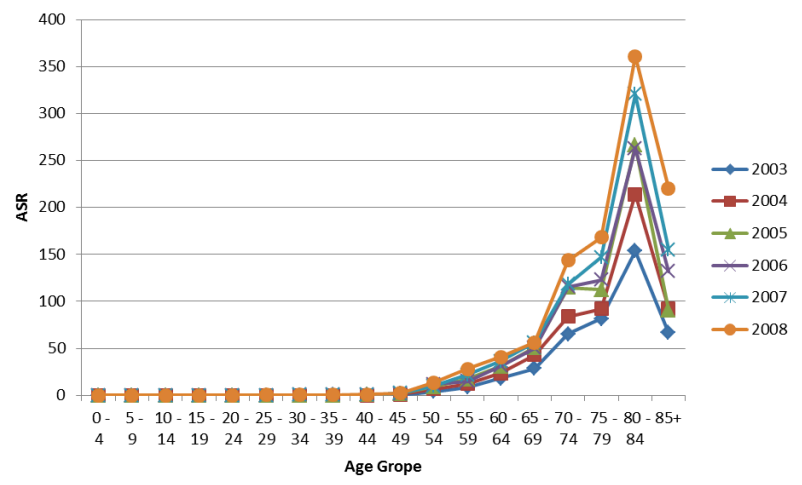

Figure 1. Change in Age-Specific Incidence (ASR) of Prostate Cancer between Age Group in Iran from 2003 to 2008

Table 1. Cumulative Incidence of Carcinoma and Adenocarcinoma of Prostate Cancer, According to two Types of Morphology and of All Age Groups, During the Years 2003 to 2008

\begin{tabular}{|l|c|c|c|c|c|c|c|c|c|c|c|}
\hline & $00-09$ & $10-19$ & $20-29$ & $30-39$ & $40-49$ & $50-59$ & $60-69$ & $70-79$ & $80-80+$ & Unknown & Total \\
\hline Adenocarcinoma & 0 & 0 & 11 & 34 & 172 & 1298 & 4033 & 6485 & 2895 & 373 & 15301 \\
\hline Carcinoma & 0 & 0 & 0 & 0 & 3 & 16 & 39 & 65 & 43 & 2 & 168 \\
\hline Total & 3 & 1 & 12 & 39 & 183 & 1390 & 4179 & 6783 & 3067 & 411 & 16071 \\
\hline
\end{tabular}


Prostate Cancer in Iran: Trends in Incidence and Morphological and Epidemiological Characteristics

Table 2. Frequency, Crude and Standardized Incidence of Prostate Cancer and the Total Number of Cancer Cases by Sex, During The Years 2003 To 2008

\begin{tabular}{|c|c|c|c|c|c|}
\hline & $\begin{array}{c}\text { The number of cases of pros- } \\
\text { tate cancer (men) }\end{array}$ & $\begin{array}{c}\text { The total number of cases of } \\
\text { cancer in men (percent) }\end{array}$ & $\begin{array}{c}\text { Total cancer cases } \\
\text { (men and women) }\end{array}$ & CIR & ASR \\
\hline 2003 & 1548 & $21619(2 / 56)$ & 38468 & 4.54 & 5.40 \\
\hline 2004 & 2072 & $26743(6 / 56)$ & 47217 & 5.97 & 7.24 \\
\hline 2005 & 2722 & $31355(1 / 56)$ & 55853 & 7.53 & 9.22 \\
\hline 2006 & 2817 & $33770(49 / 56)$ & 59786 & 7.82 & 9.57 \\
\hline 2007 & 3179 & $34636(81 / 55)$ & 62040 & 8.79 & 10.91 \\
\hline 2008 & 3733 & $42279(51 / 55)$ & 76159 & 10.37 & 12.80 \\
\hline
\end{tabular}

Table 3. Change in the Percentage Allocated to the Morphology of Carcinoma, Adenocarcinoma and Other Morphological Data (2008-2003)

\begin{tabular}{|l|c|c|c|c|c|c|}
\hline \multirow{2}{*}{} & \multicolumn{2}{|c|}{$2003-2008$} & \multicolumn{2}{c|}{$2003-2006$} & \multicolumn{2}{c|}{$2006-2008$} \\
\cline { 2 - 6 } & AAPC & $95 \%$ CI & APC & $95 \%$ CI & APC & 95\% CI \\
\hline Carcinoma & 5.9 & -43.1 to 97.1 & & & -3.3 \\
\hline Adenocarcinoma & $-1.4^{*}$ & -1.8 to -1.1 & -0.2 & -2.3 to 2.0 & -7.4 to 0.9 \\
\hline Other & $42.7^{*}$ & 12.3 to 81.3 & & & & \\
\hline
\end{tabular}

*APC and AAPC is significantly different from zero at alpha $=0.05$

annual percentage change (APC) for cancer incidence was equal to $17.29 \%$ (CI: 11.1 to 23.9) (Table 2).

\section{Morphological Trend}

The morphology of adenocarcinoma with 15301 cases $(95.21 \%)$ and carcinoma in 168 cases $(1.04 \%)$ were the most common morphology. Significant differences between the morphology of prostate cancer and the different age groups was not observed (P-Value $>0.05$ ) and nearly all the morphological occur more in older age (Table 1). Adenocarcinoma in 2003 and 2008, respectively, $97.61 \%$ and $90.97 \%$ of total prostate cancer accounted. Dedicated to the trend of changes in most common morphology (adenocarcinoma) annual percentage changes (APC) showed a significant decrease (Table 3 ).

\section{Discussion}

Our findings showed that the majority of cases (96\%) occur after 50 years and the high incidence was 80 to 84 years .a study (Fatemah Haghighi et al., 2005) conducted in Birjand (East of Iran) showed more cases occur after 50 years and prostate cancer is the most frequent in the ninth decade of life (80 years and above), which is consistent with the results of this study.

In another study in the Fars province, it also found that $99 \%$ of cases occur in man over 50 years and the highest incidence of cancer is at the age of 80 years (Farahmand et al., 2013). A study in the Khuzestan province showed that more than $99 \%$ cases were 45 years and the high incidence was 75 to 84 years (Amoori et al., 2014).

A another study conducted in the Babol city also found that the highest age of developing cancer was 70 years (Hahiyan et al., 2003) and Basiri also showed that the maximum age was 70 years (Basiri et al., 2014). One study was conducted in Turkey showed that the maximum age for the incidence cancer was 75 to 79 year (Eser et al., 2009) and Another study reported in Greece the incidence was 7o- to 75 years (Grivas et al., 2012), This difference may be due to differences in the age composition of the population.

As the incidence of prostate cancer increases, the age increases (Eser et al., 2009) and after 50 years it raises with a steep ascent (Muir et al., 1991; Fatemah Haghighi et al., 2005; Grivas et al., 2012; Farahmand et al., 2013). However, in another study in America it was as steep as after 65 years (Gronberg, 2003). In a study it was in Turkey 40 years (Zorlu et al., 2014)and in Greece 45 years reported (Grivas et al., 2012). This could be due to racial differences and genetic and environmental factors, such as diet, environment, occupation, smoking, and other unknown risk factors.

In this study, the standardized incidence of prostate cancer in 2003 to 2009 was 5.4, 7.24, 9.22, 9.57, 10.91, and 12.80 cases per 100,000 people, respectively. According to the GLOBOCAN report in 2002, the age standardized incidence rate of prostate cancer in the world was 25.3 cases per 100,000 people so this rate in developed countries (the highest was related to United States (U.S) was 56.2 and in developing countries, 9.4 cases per hundred thousand people (the minimum for Bangladesh) (Baade et al., 2009; Jack et al., 2010). Also the rate in Greece between 1999 to 2004 was 26 per hundred thousand people (Grivas et al., 2012), but the rate in 2002 have been reported about 3.5 per hundred thousand people in the Fars province (Masoompour et al., 2011) and in this study it was 5.4 per hundred thousand, which reflects the low rate of this cancer in the Iran compared to other countries.

This rate in Turkey in 2006 was equal to 22.8 (Eser et al., 2009)and in Greece had risen to 42 per hundred thousand people until 2010 (Grivas et al., 2012), Also in developed countries in 2008 it has increased to 62 cases and in the developing countries to 12 cases per hundred thousand people (Jemal et al., 2011) .In this study, the rate was 12.8 per hundred thousand people. This shows 
that the country is better for the development so prostate cancer increases. This could be due to improved reporting systems in developing countries and developed countries versus less developed countries. Although some of this difference could be real. The standardized incidence rate in this study was lower than developed and developing countries. However, the increasing trend over the years has been globally observed. This could be due to better detection tests, an aging population, and a real increase in the world. At the same time, however, the incidence of prostate cancer has been decreasing in most European countries (Bray et al., 2010). This can be due to screening programs that have already been implemented in the community.

The highest incidence in this study occur in 2008, similar to the incidence in developing countries (Jemal et al., 2011), while in another study greatest incidence was 16.65 in 2007 and with slight differences the incidence of 16.02 in 2008 was ranked as second (Farahmand et al., 2013). This may be due to differences in population, better detection methods, or whether this difference is real. However, the findings of this study are consistent with increasing incidence.

In the present study, the morphology of Adenocarcinoma was the most frequent type with $95.21 \%$ percent and carcinoma is the most common, followed by 1.04 percent. In a study showed that morphology with adenocarcinoma was greatest with 91.2 percent (Esmail Nasab N, 2007). In another study, the type of adenocarcinoma with $91.7 \%$ was allocated to the most common type (Fatemah Haghighi et al., 2005). General Urology by smith, stated that more than $95 \%$ of prostate cancers were adenocarcinoma (Fatemah Haghighi et al., 2005). In another study based on samples taken in Imam Khomeini Hospital, Pathology Center (SID) and the center of Pathology, School of Medicine, Yazd ,the most common types were adenocarcinoma, 91.4\%, 84.7\% and $71 \%$, respectively (Jamali and Moghadam, 1996). All these findings are consistent with each other and show that the most common type morphology of cancer in Iran. In a study in Saudi Arabia and Pakistan, adenocarcinoma is also the most common type morphology (Arshad and Ahmad, 2013; Albasri et al., 2014).

In addition to the lower prevalence of risk factors for prostate cancer, incomplete and the lack of comprehensive programs especially in the case of prostate cancer, breast, and colorectal cancer can be one of the main reasons for low as well as in developing countries (Mousavi et al., 2009). These limitations can lead to underestimation of the true extent of this type of cancer (Masoompour et al., 2011). In other studies, one of the most important factors of prostate cancer in developed countries was comprehensive review of the prostate cancer screening program with use of PSA (prostate specific antigen) (Jemal et al., 2011; Belbase et al., 2013).

Based the results of this study and other similar studies (Farahmand et al., 2013) have been identified in Iran that this type of cancer had the slight increase in the past years that may indicate that cancer registration data is better.

Based on these results and considering the prevalence of prostate neoplasms and adverse effects, it is suggested that most epidemiological studies in order to identify regional risk factors and lifestyles, application new screening methods for early diagnosis of latent prostate cancer .

\section{References}

Albasri A, El-Siddig A, Hussainy A, et al (2014). Histopathologic characterization of prostate diseases in Madinah, Saudi Arabia. Asian Pac J Cancer Prev, 15, 4175.

Amoori N, Mirzaei M, Cheraghi M (2014). Incidence of cancers in kuzestan province of Iran: Trend from 2004 to 2008. Asian Pac J Cancer Prev, 15, 8345-9.

Arshad H, Ahmad Z (2013). Overview of benign and malignant prostatic disease in Pakistani patients: a clinical and histopathological perspective. Asian Pac J Cancer Prev, 14, 3005-10.

Autorino R, Di Lorenzo G, Damiano R, et al (2009). Pathology of the prostate in radical cystectomy specimens: a critical review. Surgical Oncol, 18, 73-84.

Baade PD, Youlden DR, Krnjacki LJ (2009). International epidemiology of prostate cancer: geographical distribution and secular trends. Molecular nutrition Food Res, 53, 171-84.

Basiri A, Shakhssalim N, Jalaly NY, et al (2014). Difference in the incidences of the most prevalent urologic cancers from 2003 to 2009 in Iran. Asian Pac J Cancer Prev, 15, 1459-63.

Belbase NP, Agrawal CS, Pokharel PK, et al (2013). Prostate cancer screening in a healthy population cohort in Eastern Nepal: an explanatory trial study. Asian Pac J Cancer Prev, 14, 2835-8.

Bray F, Lortet-Tieulent J, Ferlay J, et al (2010). Prostate cancer incidence and mortality trends in 37 European countries: an overview. Eur J Cancer, 46, 3040-52.

Eser S, Yakut C, Ozdemir R, et al (2009). Cancer incidence rates in Turkey in 2006: a detailed registry based estimation. Asian Pac J Cancer Prev, 11, 1731-9.

Esmail Nasab N MG, Zareie M, et al (2007). Survey of epidemilogic status and incidence rates of cancers in the patients above 15 years old in Kurdistan province. SJKUMS, 11, 18-25.

Farahmand M, Almasi-Hashiani A, Mehrabani D (2013). The epidemiologic study of prostate cancer in Fars province, Southern Iran (2003-2008). Arak Med U J, 15, 54-60.

Fatemah Haghighi, Ali Habibi, Tavakoli M (2005). Epidemiological retrospective study of neoplasms of prostate gland in Birjand (South Khorasan province). $J$ Birjand $U$ Med Sci, 12, 9-15.

Ferlay J, Soerjomataram I, Dikshit R, et al (2015). Cancer incidence and mortality worldwide: sources, methods and major patterns in GLOBOCAN 2012. Int J Cancer, 136, 359-86.

Fritz AG (2000). International classification of diseases for oncology: ICD-O, World Health Organization.

Goya M (2007). Iranian Annual Cancer Registration Report 2005/2006. Ministry of Health and Medical Education, Health Deputy. Center Disease Control Prevention (in Persian).

Grivas N, Hastazeris K, Kafarakis V, et al (2012). Prostate cancer epidemiology in a rural area of North Western Greece. Asian Pac J Cancer Prev, 13, 999-1002.

Gronberg H (2003). Prostate cancer epidemiology. Lancet, 361, 859-64.

Hahiyan K, Firozjahi A, Taghkiya M (2003). Pattern of Age Distribution of Different Cancers Babol, 2001. Pejouhesh, 27, 239-45.

Hosseini S, Danesh A, Parvin M, et al (2007). Incidental prostatic adenocarcinoma in patients with PSA less than $4 \mathrm{ng} / \mathrm{mL}$ 
undergoing radical cystoprostatectomy for bladder cancer in Iranian men. Int Braz J urol, 33, 167-75.

Jack RH, Davies EA, Moller H (2010). Prostate cancer incidence, stage at diagnosis, treatment and survival in ethnic groups in South East England. BJU Int, 105, 1226-30.

Jamali M, Moghadam K (1996). Statistical study and review of prostatic latent carcinoma. Tehran U Med J, 54, 37-41.

Jemal A, Bray F, Center MM, et al (2011). Global cancer statistics. CA Cancer J Clin, 61, 69-90.

Keyghobadi N, Rafiemanesh H, Mohammadian-Hafshejani A, et al (2015). Epidemiology and trend of cancers in the province of Kerman: southeast of Iran. Asian Pac J Cancer Prev, 16, 1409-13.

Kim HJ, Fay MP, Feuer EJ, et al (2000). Permutation tests for joinpoint regression with applications to cancer rates. Statistics Med, 335-51.

Masoompour SM, Yarmohammadi H, Rezaianzadeh A, et al (2011). Cancer incidence in southern Iran, 1998-2002: Results of population-based cancer registry. Cancer Epidemiol, 35, 42-7.

Mehrabani D, Tabei S, Heydari S, et al (2008). Cancer occurrence in fars province, southern Iran. Iranian Red Crescent Med $J, \mathbf{1 0}, 314-22$.

Mousavi SM, Gouya MM, Ramazani R, et al (2009). Cancer incidence and mortality in Iran. Ann Oncol, 20, 556-63.

Muir C, Nectoux J, Staszewski J (1991). The epidemiology of prostatic cancer: geographical distribution and time-trends. Acta Oncologica, 30, 133-40.

Pakzad R, Mohammadian-Hafshejani A, Ghoncheh M, et al (2015). The incidence and mortality of prostate cancer and its relationship with development in Asia. Prostate Int, 3, $135-40$.

Pourmand G, Salem S, Mehrsai A, et al (2007). The risk factors of prostate cancer: a multicentric case-control study in Iran. Asian Pac J Cancer Prev, 8, 422.

Radmard AR (2010). Five common cancers in Iran. Arch Iran Med, 13, 143-6.

Sadjadi A, Nooraie M, Ghorbani A, et al (2007). The incidence of prostate cancer in Iran: results of a population-based cancer registry. Arch Iran Med, 10, 481-5.

Zorlu F, Zorlu R, Divrik R, et al (2014). Prostate cancer incidence in Turkey: an epidemiological study. Asian Pac J Cancer Prev, 15, 9125-30. 